\title{
Atributos físicos do solo de florestas urbanas como indicadores de degradação
}

\section{Physical attributes of the soil of urban forests as environmental indicators of environmental degradation}

\author{
Gabriela Manente Rocha', Joice Machado Garcia ${ }^{\mathrm{II}}$, \\ Alessandra Leite da Silva ${ }^{\mathrm{III}}$, Regina Márcia Longo ${ }^{\mathrm{IV}}$
}

\begin{abstract}
Resumo
A falta de planejamento urbano tem levado ao crescimento desordenado das cidades e a problemas sociais e ambientais como: a falta de saneamento básico, a poluição hídrica do ar e do solo, o desmatamento, dentre outros e também à fragmentação dos ecossistemas naturais. Nesse contexto, em áreas urbanas é possível observar um número menor e cada vez mais degradado de fragmentos florestais, sobretudo nas suas bordas, em razão de alteração física dos solos nesses locais, dentre outros fatores de degradação. Diante disso, o presente trabalho teve como objetivo analisar a degradação física do solo nas áreas de borda de dois fragmentos florestais localizados na Bacia Hidrográfica do Ribeirão Anhumas, em Campinas-SP. Para tanto, foram avaliados os índices físicos dos solos, além do Índice de Área Foliar (IAF) e do Índice de Avermelhamento do Solo (IAV). As amostras foram coletadas em pontos equidistantes entre 70 e 80 metros e a 20 metros da borda em cada fragmento de interesse. Com os resultados obtidos, procedeu-se à Análise de Componentes Principais (ACP) a fim de identificar se existem correlações entre os indicadores analisados. As análises físicas do solo indicaram que ambos os remanescentes se encontram em estágio de degradação avançado. Um deles, porém, apresentou resultados com maiores variações em todos os parâmetros físicos analisados. Apesar de não ter sido identificada correlação entre os índices físicos, o IAF e o IAV, os parâmetros são eficientes na análise e identificação da degradação do solo e os resultados contribuem para o estabelecimento de uma proposta de recuperação dessas áreas.
\end{abstract}

Palavras-chave: Bacia do Ribeirão Anhumas; Parâmetros Físicos do Solo; Fragmentos Florestais Urbanos

\begin{abstract}
The lack of urban planning has led to a disorderly growth in cities and to social and environmental problems such as lack of basic sanitation, water, air and soil pollution, deforestation, among others and also the fragmentation of natural ecosystems. In this context, it is possible to observe, in urban areas, a smaller and increasingly degraded number of forest fragments, especially on their edges, due to the physical alteration of the soils in these places, among other factors of degradation. Therefore, the present study aimed to analyze the physical degradation of the soil in the border areas of two forest fragments located in 'Ribeirão Anhumas' Hydrographic Basin, in Campinas, São Paulo state. To do so, the physical indexes of the soils, in addition to the Leaf Area Index (LAI) and the Soil Reddening Index (SRI) were evaluated. The samples were collected at equidistant points between 70 and 80 meters and 20 meters from the edge in each fragment of interest. Along with the results obtained, the Principal Components Analysis (PCA) was carried out in order to identify whether there are correlations between the analyzed indicators. Physical analyzes of the soil indicated that both remnants are in an advanced stage of degradation. One of them, however, presented results with greater variations in all the analyzed physical parameters. Although no correlation has been identified between the physical indices, LAI and SRI, the parameters are efficient in the analysis and identification of the soil degradation, and the results contribute to the establishment of a proposal for the recovery of these areas.
\end{abstract}

Keywords: Ribeirão Anhumas Basin; Physical Parameters of the Soil; Soil degradation; Urban Forest Fragments

Engenheira Ambiental e Sanitarista, Centro de Ciências Exatas, Ambientais e de Tecnologia, Pontifícia Universidade Católica de Campinas, Rod. Dom Pedro I, km 136, CEP 13086-900, Campinas (SP), Brasil. gmrocha28@gmail.com (ORCID: 0000-0002-9392-2615)

II Engenheira Ambiental e Sanitarista, Mestranda em Sistemas de Infraestrutura Urbana, Centro de Ciências Exatas, Ambientais e de Tecnologia, Pontifícia Universidade Católica de Campinas, Rod. Dom Pedro I, km 136, CEP 13086-900, Campinas (SP), Brasil. joiice_garcia@hotmail.com (ORCID: 0000-0003-3395-9384)

III Engenheira Ambiental e Sanitarista, Me., Doutoranda em Ciências Ambientais, Instituto de Ciência e Tecnologia, Universidade Estadual Paulista “Júlio de Mesquita Filho”, Av. Três de Março, 511, CEP 18087-180, Sorocaba (SP), Brasil. alessandra_ls@yahoo.com (ORCID: 0000-0001-6534-2122)

IV Engenheira Agrônoma, Dra., Docente e Pesquisadora do Programa de Pós Graduação em Sistemas de Infraestrutura Urbana, Centro de Ciências Exatas, Ambientais e de Tecnologia, Pontifícia Universidade Católica de Campinas, Rod. Dom Pedro I, km 136, CEP 13086-900, Campinas (SP), Brasil. regina.longo@puc-campinas.edu.br (ORCID: 0000-0002-2374-4649) 


\section{Introdução}

As atividades econômicas das sociedades atuais apresentam forte dependência de fornecimento de recursos e serviços dos ecossistemas naturais, tanto para a sobrevivência individual do homem quanto para a satisfação das necessidades sociais. Isso, consequentemente, pode gerar desequilíbrio ambiental, ao desencadear impactos e alterações no ambiente, com reflexos na própria qualidade de vida da população (BELLO; HUFFNER, 2012). Dessa maneira, destaca-se a relevância de estudos a respeito da degradação ambiental em ambientes urbanos, visto que nesses locais as alterações ambientais são frequentemente elevadas. Portanto há a necessidade de se identificar essas alterações ambientais e sociais dentro das bacias hidrográficas, pois estas são unidades de planejamento ambiental e de estudos (NASCIMENTO; VILLAÇA, 2008).

A falta de planejamento é um problema comum nas bacias hidrográficas urbanas. As cidades crescem de modo desordenado, associado a uso e ocupação que danificam o ambiente, causando vários problemas como: poluição atmosférica, hídrica e dos solos, déficit de higiene e saneamento básico, desmatamento intensivo e indiscriminado, afetando a biodiversidade, gerando alterações até mesmo dos cursos dos rios em termos de volume e qualidade da água, dentre outros problemas que afetam, sobretudo, as zonas de expansão urbana e que alteram a paisagem urbana (DAMAME; OLIVEIRA; LONGO, 2019).

Um dos problemas relacionados aos ecossistemas florestais é o efeito de borda, o qual reduz a biodiversidade, tanto da fauna quanto da flora dos fragmentos, em função das alterações físicas, químicas e biológicas que a área passa a sofrer, o que gera impedimentos às trocas genéticas entre as espécies, ou seja, o fragmento fica isolado e cada vez mais se torna menor (LIMA-RIBEIRO, 2008). Dessa forma, fica evidente o papel dos corredores ecológicos, os quais desempenham a função de interligar os fragmentos florestais urbanos, com a estratégia de aumentar os fluxos gênicos entre a fauna e a flora existente, assim como exercem a função de habitat, fornecendo áreas dotadas de recursos e condições apropriadas para a sobrevivência das espécies, além de proteger os remanescentes florestais em um contexto geral (RIBEIRO, 2010).

Nesse contexto, entende-se que, para os projetos de recuperação de áreas degradadas e de implantação de corredores ecológicos obterem sucesso, é necessário um entendimento adequado do solo/substrato onde esse processo irá ocorrer. Para isso, é preciso definir indicadores ecológicos que são importantes componentes de avaliação ambiental, capazes de quantificar alterações na qualidade do meio ambiente e quantidade de recursos naturais, assim como de avaliar os esforços desenvolvidos visando à melhoria do meio ambiente ou a mitigação de sua degradação (MATTAR; KRUGER; DZIEDZIC, 2009).

Diante disso, o presente trabalho propôs analisar a degradação física dos solos nas áreas de borda de dois fragmentos florestais localizados na Bacia Hidrográfica do Ribeirão Anhumas, no município de Campinas (SP), por meio de parâmetros físicos do solo (índices físicos como densidade, peso específico natural, umidade, porosidade, entre outros), buscando correlações com o Índice de Área Foliar (IAF) e o Índice de Avermelhamento do Solo (IAV), a fim de indicar medidas corretivas que auxiliem na implantação do corredor ecológico.

\section{Material e métodos}

\section{Caracterização da área de estudo}

A Bacia do Ribeirão Anhumas está situada no município de Campinas-SP e abrange uma área aproximada de $150 \mathrm{~km}^{2}$. Localiza-se entre as coordenadas geográficas $22^{\circ} 45^{\prime} 15^{\prime \prime}$ e $22^{\circ} 55^{\prime} 50^{\prime \prime}$ de latitude sul e $46^{\circ} 58^{\prime} 55^{\prime \prime}$ e $47^{\circ} 60^{\prime} 55^{\prime \prime}$ de longitude oeste e situa-se na transição entre o Planalto Atlântico e a Depressão Periférica. O Ribeirão Anhumas é afluente do rio Atibaia e sua bacia 
hidrográfica drena também uma pequena parcela ao sul do município de Paulínia.

Trata-se de uma das bacias hidrográficas mais degradadas de Campinas devido à crescente urbanização e à expansão urbana sem planejamento territorial, que resultou em uma variedade de problemas ambientais, como: desmatamento de matas ciliares, alterações nos cursos dos rios, perda da biodiversidade, descartes inadequados de efluentes, contribuindo para a contaminação hídrica e até mesmo do solo, além de outros problemas (FRANCISCO et al., 2008).

A análise dos indicadores foi realizada na borda de dois remanescentes florestais urbanos localizados na região do baixo curso do Ribeirão Anhumas, denominados como Fazenda Anhumas (FAN) e Fazenda Argentina (FAR). Esses fragmentos pertencem ao corredor ecológico "Mata Santa Genebrinha", oficializado pela Prefeitura Municipal de Campinas (CAMPINAS, 2016) com o intuito de conectar a Mata Santa Genebra. Na Figura 1, é possível visualizar o corredor ecológico, assim como os fragmentos florestais urbanos focados neste estudo, os quais são identificados pelas letras "C" (Fazenda Anhumas) e "G" (Fazenda Argentina).

\section{Figura 1 - Localização das áreas "C" (Fazenda Anhumas) e "G” (Fazenda Argentina)}

Figure 1 - Localization of Areas "C" (Anhumas Farm) and "G" (Argentine Farm)

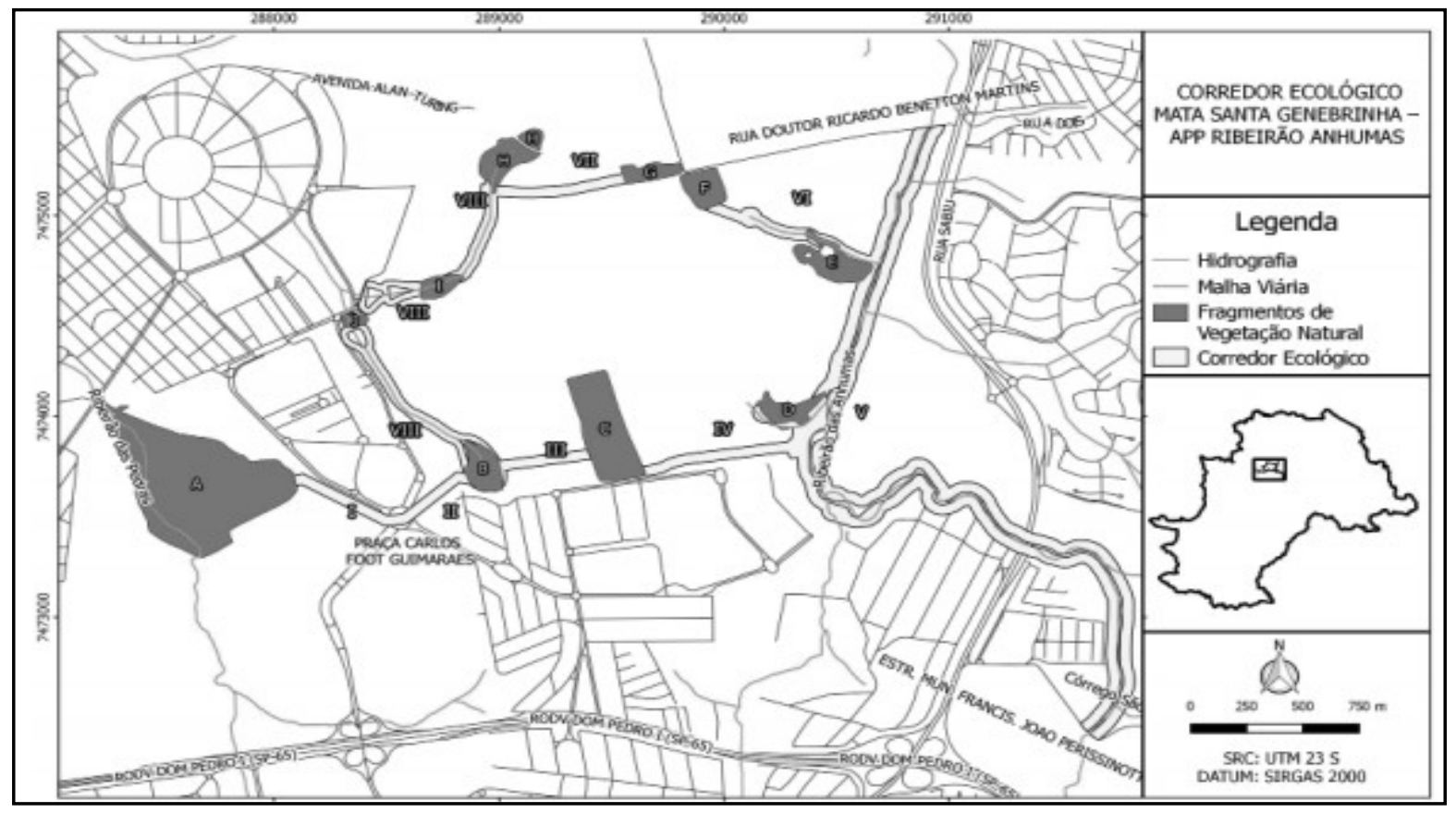

Fonte: Diário Oficial - Prefeitura Municipal de Campinas (2016)

Segundo dados de solos do Brasil, disponibilizados pelo INPE (INSTITUTO BRASILEIRO DE PESQUISAS ESPACIAIS, 2020) e abordados no estudo de Silva et al. (2019), identificou-se que o solo encontrado nos fragmentos florestais em estudo pertence à classe LVA5, ou seja, latossolo vermelho-amarelo moderado e proeminente com relevo suave ondulado a ondulado com associação a cambissolo A moderado com relevo ondulado a forte ondulado, ambos álicos e com textura argilosa.

Com relação à cobertura vegetal, os fragmentos analisados encontram-se sobre "Áreas de Tensão Ecológica", em que se destacam as áreas de contato entre Savana e Floresta Estacional e entre Savana e Floresta Ombrófila. A Floresta Ombrófila é típica da Mata Atlântica e se encontra principalmente ao longo do litoral, em regiões de temperatura elevada (médias de $25^{\circ} \mathrm{C}$ ) e chuvas intensas e bem distribuídas ao longo do ano, praticamente sem estação seca; em contrapartida, a Floresta Estacional abrange, sobretudo, os remanescentes de Mata Atlântica encontrados no 
interior do Estado de São Paulo. Esses dois tipos de formações florestais fazem contato ainda com a Savana (Cerrado), uma vegetação adaptada a regiões normalmente planas, com clima mais seco e vegetação predominantemente herbácea (GARCIA et al., 2019).

O remanescente da Fazenda Anhumas está disposto paralelamente às curvas de nível, ao contrário da Fazenda Argentina que as corta. No entorno dos dois fragmentos pode ser encontrado cultivo de cana de açúcar, sendo ainda verificada pastagem ao norte e oeste da Fazenda Anhumas e a sul da Fazenda Argentina, sendo que nesta há uma conexão com outro remanescente (Figura 2).

\section{Coleta das amostras}

A amostragem de solo ocorreu no mês de junho de 2015 no entorno dos perímetros dos dois remanescentes florestais (Fazenda Anhumas - FAN e Fazenda Argentina - FAR). O remanescente Fazenda Anhumas apresenta uma área de 10,51 ha em cuja borda foram coletadas amostras em 18 pontos equidistantes 70 metros entre si e 20 metros da borda (Figura 2a). Na Fazenda Argentina, a qual possui uma área de 2,97 ha, a coleta consistiu em 8 pontos distribuídos de forma similar à anterior (Figura $2 b$ ).

Figura 2 - a) Pontos de amostragem na Fazenda Anhumas. b) Pontos de amostragem na Fazenda Argentina

Figure 2 - a) Sampling points in "Fazenda Anhumas". b) Sampling points in "Fazenda Argentina”

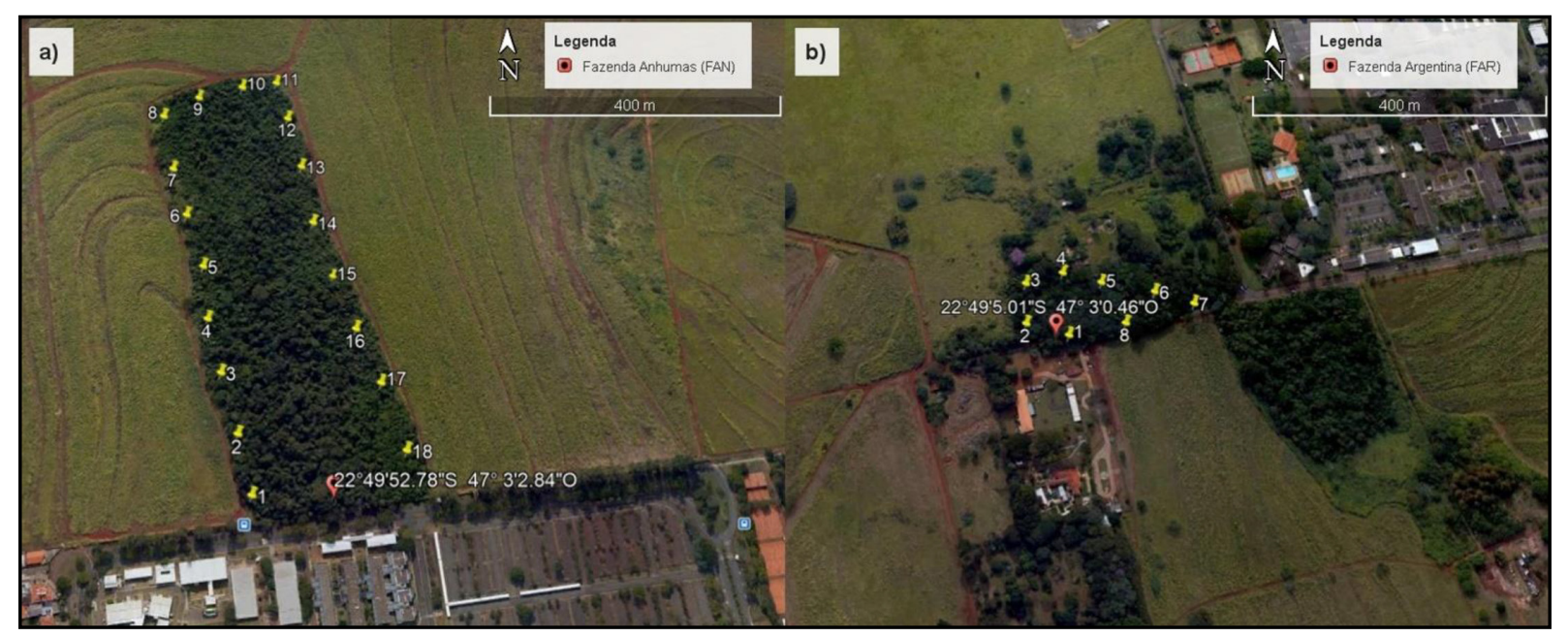

Fonte: Autores (2019)

Foram realizadas coletas de amostras de solo indeformadas e deformadas. Para o primeiro tipo, utilizou-se um anel metálico com diâmetro de $4,6 \mathrm{~cm}$ e altura de $4,8 \mathrm{~cm}$, o qual foi introduzido ao solo até a profundidade de aproximadamente $20 \mathrm{~cm}$. Para o segundo, as amostras deformadas compostas foram retiradas com um trado na profundidade de $0-20 \mathrm{~cm}$. As amostras foram acondicionadas em sacos plásticos e devidamente identificadas e encaminhadas ao laboratório para secagem e obtenção da Terra fina Seca ao Ar (TFSA).

Os parâmetros físicos do solo avaliados foram a Densidade do solo (Den), os Pesos Específicos (Natural, dos Sólidos, Aparente Seco, Saturado, Submerso), a Umidade, a Porosidade total calculada (Por), o Grau de Saturação e o Índice de Vazios. As análises foram realizadas de acordo com as normas ABNT NBR 9813 (2016), ABNT NBR 16097 (2012) e ABNT NBR 6458 
(2017).

As fotografias hemisféricas foram obtidas nos pontos da borda dos remanescentes florestais em junho de 2015, período de inverno no hemisfério sul. Os valores de Índice de Área Foliar (IAF) foram obtidos por meio de análise das citadas fotografias no software HemiView@. Este, com a data de tiragem da fotografia, juntamente com as suas coordenadas geográficas, conseguiu analisar e classificar a quantidade de luz (pixels brancos) e a biomassa vegetal (pixels negros) em anéis de largura definida (GARCIA et al., 2018).

O Índice de Avermelhamento do Solo (IAV) foi obtido pela determinação da cor efetuada no campo em amostras de solo úmido, empregando-se a carta de Munsell. A partir da avaliação do matiz, valor e croma, foi calculado o índice de avermelhamento (IAV) (TORRENT; BARRÒN, 1993 apud SANTANA et al., 2013) conforme Equação (1):

$$
I A V=(10-M) \times C V
$$

Em que: $\mathrm{M}=\operatorname{matiz}(7.5 \mathrm{R}=0 ; 10 \mathrm{R}=1 ; 2.5 \mathrm{YR}=2 ; 5 \mathrm{YR}=3 ; 7.5 \mathrm{YR}=4 ; 10 \mathrm{YR}=5 ; 25 \mathrm{YR}=6 ; 2.5 \mathrm{Y}=7) ; \mathrm{C}=$ croma; $\mathrm{V}=$ valor.

\section{Tratamento e interpretação dos dados}

Os resultados encontrados foram dispostos em gráficos bloxspot e procedeu-se uma análise de correlação entre os parâmetros analisados, utilizando-se o Coeficiente de Correlação de Pearson. Além disso, utilizando o software estatístico SAS UniversityEdition realizou-se a Análise de Componentes Principais, a fim de compreender as interações entre os parâmetros, bem como os parâmetros mais relevantes para a análise de degradação ambiental em cada remanescente. A análise de componentes principais reduz o número de variáveis para novas variáveis, as quais são chamadas de "componentes". Essas têm a função de representar a maior parte dos dados, para que seja o mais fiel possível a eles (HONGYU; SANDANIELO; OLIVEIRA JUNIOR, 2016).

\section{Resultados e discussão}

Os resultados das análises físicas do solo dos remanescentes urbanos em estudo estão representados na Figura 3.

De maneira geral, pode-se observar que os maiores valores de densidade do solo e dos pesos específicos (natural, aparente, saturado e submerso) foram registrados na Fazenda Anhumas (FAN). Oliveira, Lima e Verburg (2015), estudando diferentes manejos de solo, observaram que estes não diferiram entre si, mas apresentaram valores mais elevados quando comparados com solo sob floresta, indicando que o manejo dos solos promove alterações em atributos físicos em diferentes intensidades.

A densidade do solo é um atributo de grande importância, pois influencia outras características físicas do solo, podendo ser alterada em função da cobertura vegetal, do teor de matéria orgânica e do manejo(REICHARDT; TIMM,2008). Um solo denso apresenta uma redução nos poros, na permeabilidade e na infiltração de água, o que dificulta o estabelecimento da cobertura vegetal, bem como a recuperação das áreas degradadas por revegetação. No fragmento Fazenda Anhumas (FAN), os valores de densidade do solo ficaram entre 1,0 a 1,2 $\mathrm{g} \mathrm{cm}^{-3}$, enquanto na Fazenda Argentina (FAR) entre 0,80 a $0,85 \mathrm{~g} \mathrm{~cm}^{-3}$.

Em estudo realizado em uma microbacia hidrográfica no município de Alegre - ES, Guariz et al. (2009), ao avaliarem dados de densidade em latossolos vermelho-amarelo, verificaram que um fragmento florestal com nível secundário de desenvolvimento apresentou valor de densidade de $1,47 \mathrm{~g} \mathrm{~cm}^{-3}$. Ainda, Ralisch et al. (2008) detectaram valor de $1,04 \mathrm{~g} \cdot \mathrm{cm}^{-3}$ para densidade do latossolo vermelho amarelo em área de floresta. Pandolfi et al. (2007) verificaram que a compactação do solo originada pelo uso de práticas inadequadas de manejo resulta diretamente em aumento na densidade. Dessa forma, verifica-se que o valor de densidade para o solo da Fazenda Anhumas se aproxima dos valores obtidos para mata nativa, no entanto aquele obtido na Fazenda Argentina é reduzido, sugerindo menor grau de compactação. 
Figura 3 - Resultados das análises físicas de solo nos dois remanescentes: FAN - Fazenda Anhumas e FAR - Fazenda Argentina

Figure 3 - Results of the physical soil analysis in the two remnants: FAN - Farm Anhumas and FAR - Farm Argentina

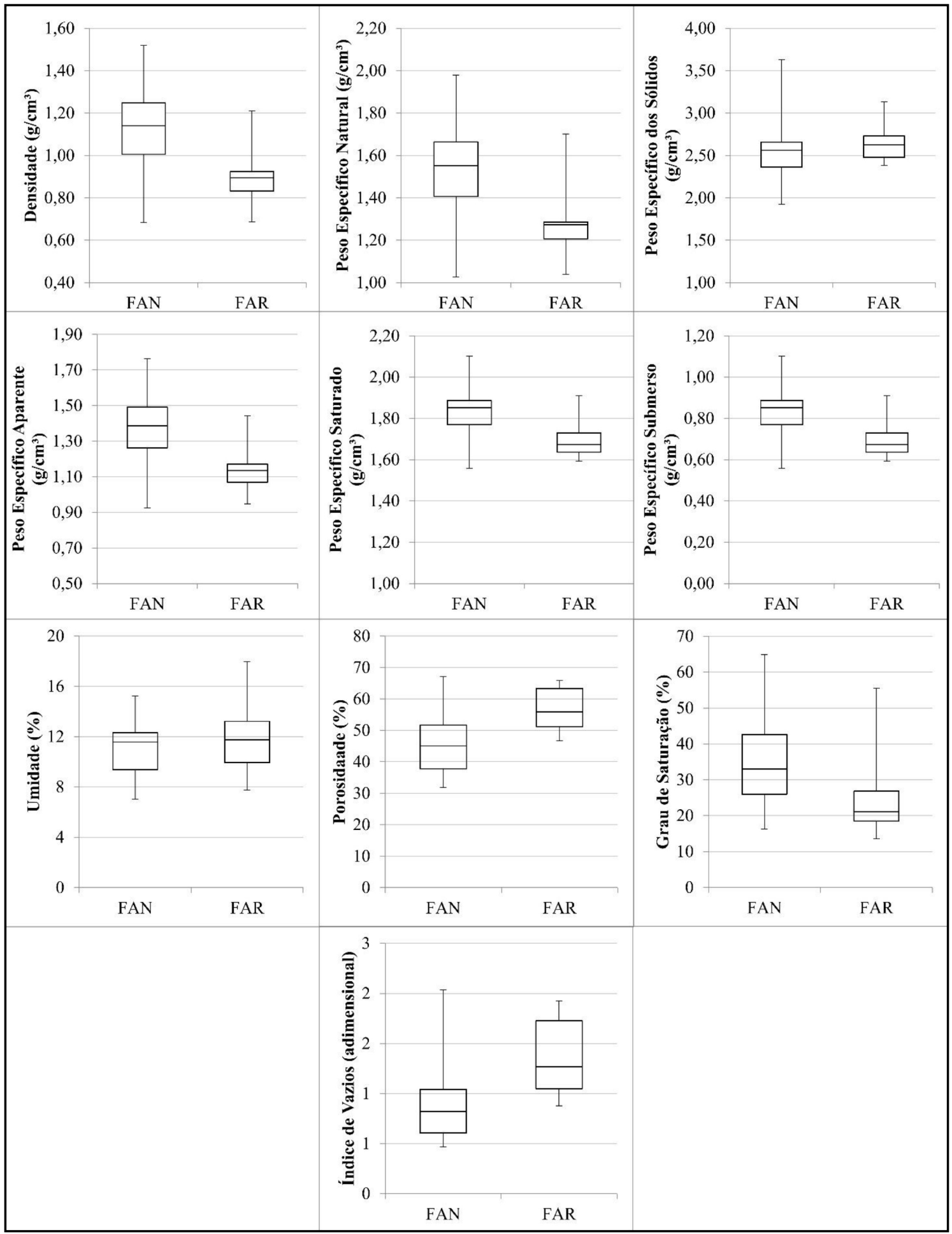

Fonte: Autores (2019) 
Em relação à porcentagem total de poros (Por), índice de vazios e umidade, pode-se observar que a Fazenda Argentina (FAR) apresentou maiores valores em relação à Fazenda Anhumas (FAN) (Figura 3). Oliveira, Lima e Verburg (2015) destacam que a porosidade total é um indicador importante da qualidade física do solo, sendo que, de modo geral, pode-se dizer que solos com uma maior porcentagem de poros resultam em condições de menor impacto sofrido em relação ao tráfego (humano, animal e por máquinas) e ao revolvimento, seja por atividades agrícolas ou mesmo urbanas. Segundo os mesmos autores, o solo sob floresta reflete a condição natural em relação ao volume total de poros, mas os sistemas de manejo reduziram a porosidade total, evidenciando a perda de qualidade física do solo nas áreas cultivadas, semelhante ao observado por Rossetti e Centurion (2013). Destaca-se que a umidade do solo é um parâmetro de grande importância para o crescimento das plantas, estando relacionada com as características temporais e de intensidade dos eventos pluviométricos (SANTOS; MONTENEGRO; SILVA, 2011), além das características físicas do solo.

No presente trabalho, verifica-se que as alterações observadas nos atributos do solo podem ter sido causadas pelas diferentes pressões que as áreas de bordas desses remanescentes vêm sofrendo, uma vez que estes se encontram no mesmo tipo de solo e possuem o mesmo tipo de cobertura vegetal original, encontrando-se também próximos um ao outro. As áreas de borda podem ser definidas como a periferia de um fragmento florestal, ou seja, consiste na região limítrofe entre uma área florestada e outras não florestadas. A principal consequência da interação dessa vegetação remanescente com novos e distintos ambientes no entorno é então denominada como efeito de borda (BLUMENFELD et al., 2016). Esses mesmos autores ainda destacam que variações nos tipos de vizinhança geram diferentes efeitos sobre os fragmentos florestais, assim a consideração da localização dos mesmos nas avaliações de sua qualidade ambiental é, portanto, de suma importância.

Compreender a evolução do uso e ocupação do solo no entorno dos remanescentes promove melhor compreensão da evolução da perturbação ambiental nessas áreas e aponta tendências para a definição das ações futuras a serem tomadas (FENGLER et al., 2015). Vasconcelos et al. (2014), comparando a porosidade total em solos sob mata nativa e diferentes sistemas de cultivos, observaram que houve redução no volume total de poros de 0,60 a $0,38 \mathrm{~m}^{3}$ $\mathrm{m}^{-3}$. É importante destacar ainda que a porosidade é relevante aos processos físicos, químicos e biológicos como: a infiltração, condutividade, drenagem, retenção de água, difusão de nutrientes, crescimento de microrganismos e raízes (PAULINO, 2013). A densidade do solo também é um parâmetro importante porque é utilizada para determinar a quantidade de água e nutrientes que existem no perfil do solo. Quanto mais denso o solo, maior a redução dos poros, lembrando ainda que a perda da porosidade pode estar relacionada também à redução do teor de matéria orgânica, esperada nesses casos (PARENTE; MAIA, 2011).

O valor médio de IAF estimado por fotografia hemisférica foi de $1,55 \mathrm{~m}^{2} / \mathrm{m}^{2}$ para a Fazenda Anhumas e de $1,46 \mathrm{~m}^{2} / \mathrm{m}^{2}$ para a Fazenda Argentina, conforme observado na Figura 4 . O IAF é utilizado para descrever a superfície fotossintética da copa das plantas, sendo definido como a quantidade de área da superfície foliar por unidade de área do solo e expresso em $\mathrm{m}^{2}$ $/ \mathrm{m}^{2}$. No entanto, recentemente a definição de IAF, foi considerada como a metade da área total da folhagem por unidade de área da superfície do solo (HEMIVIEW, 2015). É importante esclarecer que, apesar do IAF em sua definição estar relacionado apenas à área das folhas, o mesmo não faz essa diferenciação, considerando em sua análise também os galhos, flores e frutos conforme mostra a Figura 5. Todavia, apesar dessa limitação, a fotografia hemisférica apresenta-se como uma ferramenta importante e útil em estudos ecológicos (GALVANI; LIMA, 2014). 
Figura 4 - Resultados dos IAF e IAV (seco e úmido) nos dois remanescentes: FAN - Fazenda Anhumas e FAR - Fazenda Argentina

Figure 4 - Results of the IAF and IAV (dry and humid) in two remaining: FAN - Farm Anhumas and FAR - Farm Argentina

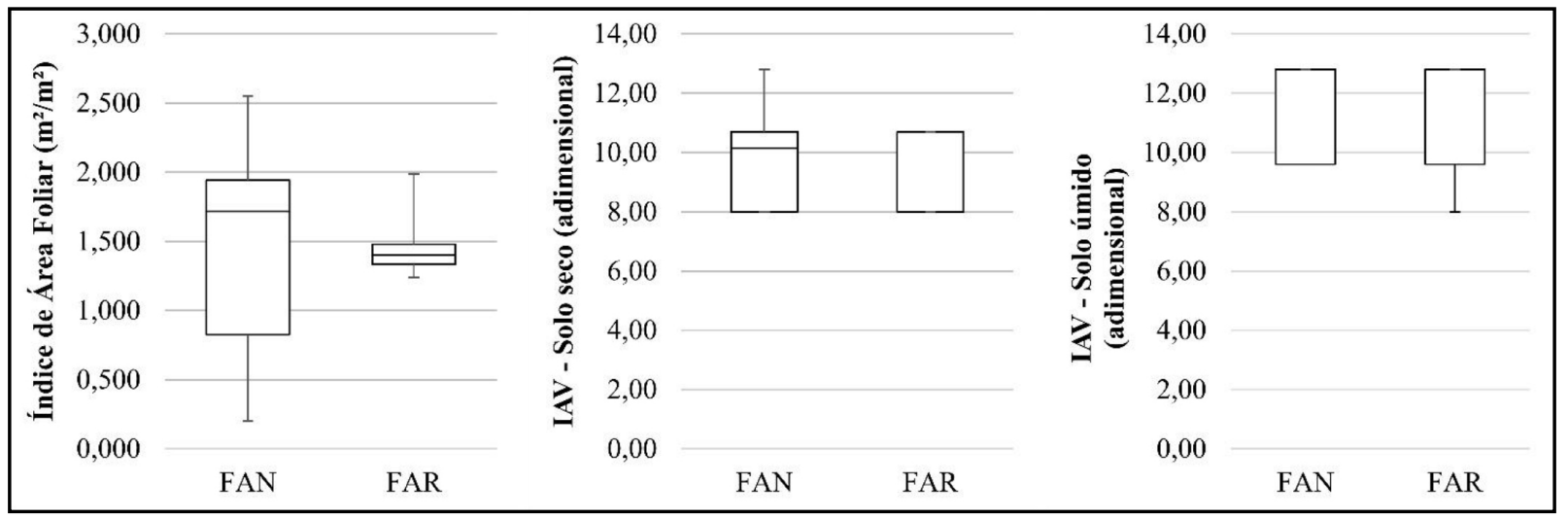

Fonte: Autores (2019)

Figura 5 - Imagem da cobertura vegetal obtida na a) Fazenda Anhumas (FAN) e b) Fazenda Argentina (FAR) utilizando a câmera Hemisférica

Figure 5 - Image of the plant cover obtained in the a) Farm Anhumas (FAN) and b) Farm Argentina (FAR) using the hemispheric camera

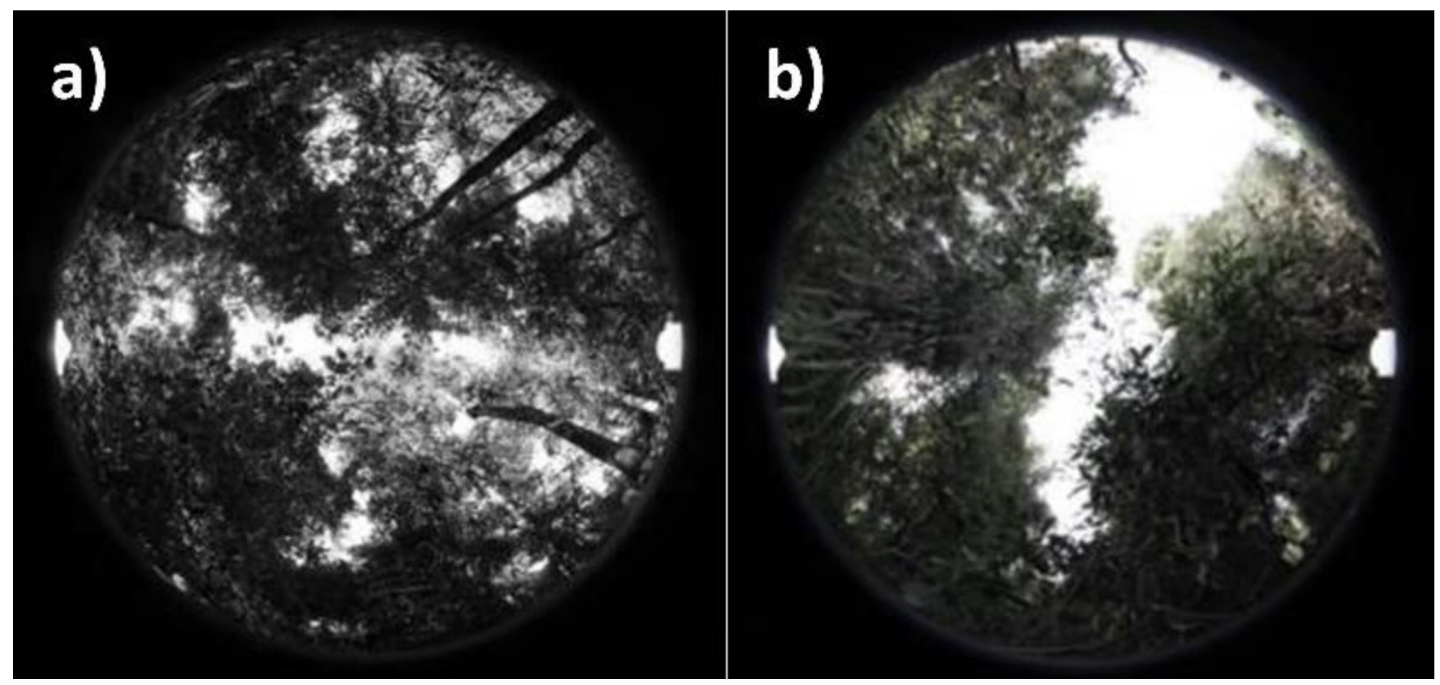

Fonte: Garcia et al. (2018)

Garcia et al. (2018), avaliando o IAF das áreas de borda e comparando com áreas internas da Mata Santa Genebra (fragmento florestal urbano que apresenta condições similares as da área de estudo), observaram que o valor médio ficou entre 2,175 e 2,037 $\mathrm{m}^{2} / \mathrm{m}^{2}$ para pontos no interior da mata. Para a área externa os valores médios variaram entre 1,845 e $1,223 \mathrm{~m}^{2} / \mathrm{m}^{2}$. Segundo os mesmos autores, o interior da mata encontra-se mais conservado que seu exterior, provavelmente em função do efeito de borda que reduz severamente as espécies, além dos problemas da pressão do entorno urbano. Resultados semelhantes foram obtidos neste trabalho 
para as áreas de borda dos fragmentos estudados. Porém, é importante destacar que o IAF sofre influências da variabilidade espacial e da variabilidade temporal: ciclos anuais e interanuais que interagem com o padrão estrutural, estratificação e homogeneidade (ZANCHI et al., 2009). Como o estudo foi realizado no inverno, as chances de serem menores os valores de IAF se elevam devido à queda das folhas e, assim, o IAF apresenta valores mais baixos.

Em relação à cor do solo, pode-se observar que todas as amostras coletadas, tanto da FAR quanto da FAN, apresentaram matiz igual a 2.5YR, vermelho-escuro. De modo geral, pode-se dizer que o IAV funciona como um indicador de degradação, pois, de acordo com Survey Staff (1993) apud Guimarães (2016), a cor do solo está diretamente relacionada às propriedades químicas e físicas do mesmo, bem como sua composição biológica e mineralógica. Considerando que os principais fatores que influenciam a cor dos solos são a mineralogia, a umidade e o conteúdo de matéria orgânica e que o IAV é um cálculo baseado nas características da cor do solo, variações relevantes no IAV podem indicar que a mineralogia, a umidade e principalmente o conteúdo de matéria orgânica do mesmo podem estar prejudicados, apontando uma possível degradação do solo estudado.

A partir dos dados obtidos aplicou-se a Análise de Componentes Principais (ACP). Na Figura 6, o percentual indicado junto a cada componente indica a quanto dos dados ela está associada, portanto são confiáveis. Os valores apontados na escala de cada componente variam de $-1,0$ a 1,0 e mostram que a proximidade entre as variáveis indica o quanto as mesmas estão correlacionadas.

\section{Figura 6 - Resultados da Análise de Componentes Principais: a) Fazenda Anhumas; b) Fazenda Argentina}

Figure 6 - Results of Principal Components Analysis: a) "Fazenda Anhumas"; b) "Fazenda Argentina”
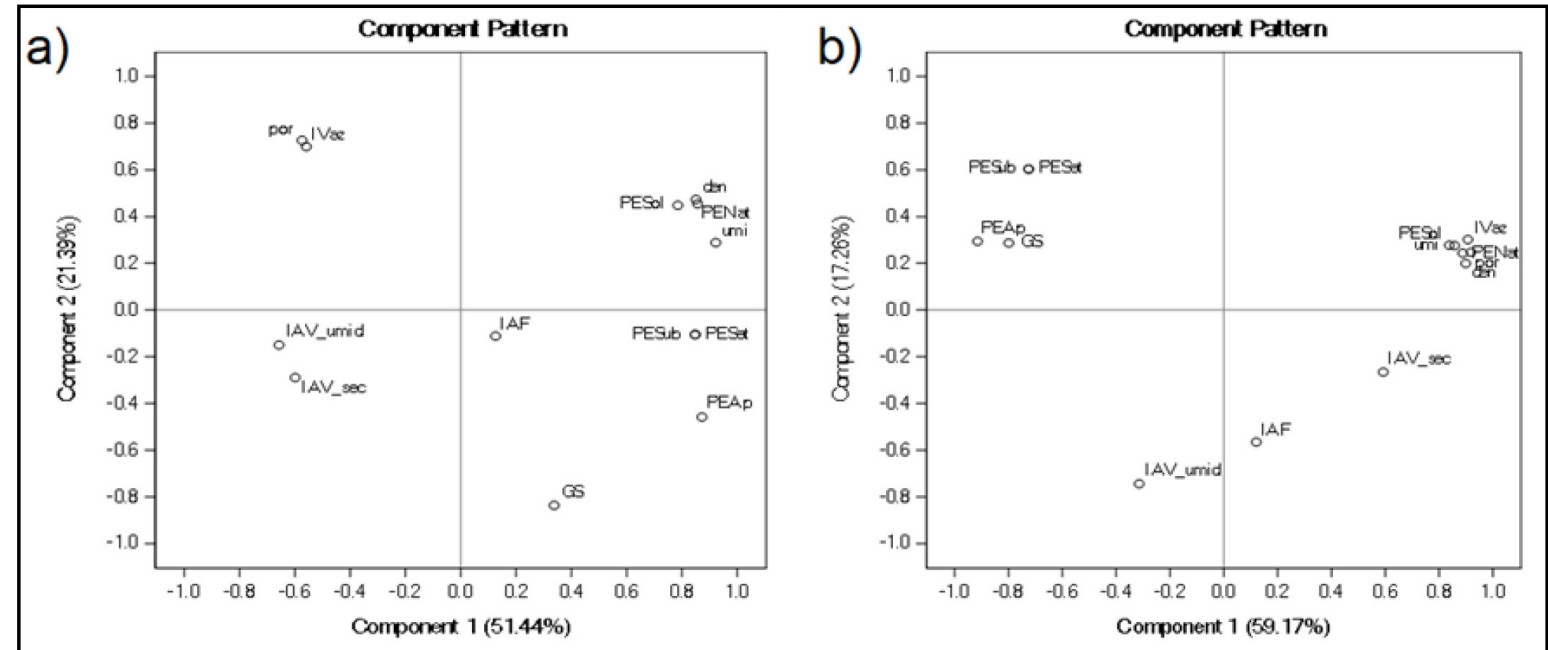

Fonte: Autores (2019)

Em que: IAF= Índice de Área Foliar, IAV_sec = (Índice de Avermelhamento do solo - seco), IAV_umid (Índice de Avermelhamento do solo - úmido) $\mathrm{PESol}=$ Peso Específico dos Sólidos, Den $=$ Densidade do solo, $\mathrm{PENat}=\mathrm{Peso}$ Específico Natural, Umi = Umidade, $\mathrm{PESub}=$ Peso Específico Submerso, PESat $=$ Peso Específico Saturado, PEAp = Peso Específico Aparente Seco, GS = Grau de Saturação, IVaz = Índice de Vazios, Por = Porosidade.

Os resultados apresentados nos gráficos da Figura 6 (a e b) indicam que as variáveis IAF, IAV seco e IAV úmido não apresentam correlação direta entre os índices físicos e os demais índices. Em relação aos demais parâmetros, foi possível notar correlações entre os índices físicos. 
No caso da FAN, as variáveis Peso Específico dos Sólidos (PESol), Densidade do solo (Den), Peso Específico Natural (PENat) e Umidade (Umi) estão correlacionadas entre si, assim como o Peso Específico Submerso (PESub) e Peso Específico Saturado (PESat) estão fortemente relacionadas, todos associados a Componente 1.

Os dados da FAR apresentam as variáveis PESol, Den, PENat, Umi, IVaz e Por fortemente correlacionadas entre si. Pode-se observar que o IVaz e a Por também estão correlacionadas na FAN, mas estão relacionados a Componente 2 , o que possivelmente se deve ao fato dos dois índices levarem em conta o que está armazenado nos poros do solo, já que a porosidade indica o quanto de fluido (ar, água ou ambos) existe nos poros e o índice de vazios indica quanto de ar está presente no solo no geral, ou seja, quanto mais compactado o solo, menor o índice de vazios. Assim, na FAR o solo tende à compactação.

Também é possível identificar como o Peso Específico Aparente Seco (PEAp) e o Grau de Saturação (GS) estão fortemente relacionados, porém no sentido negativo, associando-se a Componente 2. O Grau de Saturação indica a porcentagem volumétrica de água nos vazios do solo e o Peso Específico Aparente Seco mostra o peso do solo desconsiderando sua água, ou seja, quanto pesaria aquele solo se tivesse perdido toda sua água. Ao passo em que a primeira variável indica o quanto há de água no solo, a segunda desconsidera esse valor de água e indica o peso do solo.

\section{Conclusão}

Com a análise dos resultados obtidos, pode-se concluir que:

a) Os dois remanescentes florestais em estudo encontram-se degradados quando analisados os parâmetros de solo utilizados como indicadores, porém o remanescente denominado de Fazenda Argentina (FAR) apresentou parâmetros físicos do solo com características melhores, quando comparado à literatura do que o remanescente denominado de Fazenda Anhumas (FAN);

b) Em ambos os remanescentes em estudo há necessidade da realização de medidas de recuperação da qualidade física do solo, especialmente nas bordas, como medida inicial ao processo de recuperação e também visando o estabelecimento do corredor previsto;

c) Mesmo sendo possível identificar padrões diferentes em cada remanescente, pode-se observar por meio da Análise de Componentes Principais que os parâmetros densidade do solo, peso específico natural e peso específico dos sólidos foram os mais influentes e, portanto, essenciais, na análise da qualidade do solo, conforme a realizada no presente trabalho;

d) Não foi identificada correlação entre os índices físicos e os índices IAF e IAV. Apesar disso, pode-se observar que IAF e o IAV são parâmetros também pertinentes para avaliar a qualidade dos solos, visto serem capazes de identificar a degradação ambiental;

e) Ressalta-se que as maiores pressões que ambos os fragmentos analisados apresentam provêm da proximidade de áreas urbanas e de atividades agrícolas no entorno, especialmente o cultivo de cana-de-açúcar. Essas pressões promovem alterações físicas no solo em função de perdas de solo relacionadas aos processos erosivos, alterações na dinâmica de infiltração de água no solo e tráfego de máquinas e pessoas;

f) Portanto, é importante destacar a necessidade de conscientização ambiental da população, assim como planejamento urbano e ambiental (dentre uma das medidas destaca-se a implantação dos corredores ecológicos), a fim de mitigar os impactos existentes e evitar futuros danos.

\section{Agradecimentos}

À Fundação de Apoio à Pesquisa do Estado de São Paulo (FAPESP) pelo apoio financeiro (processo no 2018/17250-3); à Coordenação de Aperfeiçoamento de Pessoal de Nível Superior Brasil (CAPES) - Código de Financiamento 001 pela bolsa de mestrado e a FAPIC/Reitoria da PUC-Campinas pela concessão da bolsa de iniciação científica. 


\section{Referências}

ASSOCIAÇÃO BRASILEIRA DE NORMAS TÉCNICAS. NBR 6458: Grãos de pedregulho retidos na peneira de abertura $4,8 \mathrm{~mm}$ - Determinação da massa específica, da massa específica aparente e da absorção de água. Rio de Janeiro, 2017.

ASSOCIAÇÃO BRASILEIRA DE NORMAS TÉCNICAS. NBR 9813: Solo - Determinação da massa específica aparente in situ, com emprego de cilindro de cravação. Rio de Janeiro, 2016.

ASSOCIAÇÃO BRASILEIRA DE NORMAS TÉCNICAS. NBR 16097: Solo - Determinação do teor de umidade - Métodos expeditos de ensaio. Rio de Janeiro, 2012.

BELLO, L. A. L.; HUFFNER, J. G. P. Análise dos impactos ambientais da expansão urbana na Ilha de Cotijuba, Belém- PA. Revista Caminhos de Geografia, Uberlândia, v. 13, n. 44, p. 286-298, 2012.

BLUMENFELD, E. C. et al. Relações entre tipo de vizinhança e efeitos de borda em fragmento florestal. Ciência Florestal, Santa Maria, v. 26, n. 4, p. 1301-1316, 2016.

CAMPINAS. Decreto, 19.167, de 6 de julho de 2016. Estabelece diretrizes para a área de influência da linha de conectividade em acordo com decreto 19.167, de 06 de junho de 2016 que institui o plano municipal do verde e dá outras providências. Diário Oficial, Campinas, SP, jun. 2016. Disponível em: http://www.campinas.sp.gov.br/uploads/pdf/145909955.pdf. Acesso em: 01 fev. 2018.

DAMAME, D. B.; OLIVEIRA, E. D.; LONGO. R. M. Impactos ambientais pelo uso e ocupação do solo em sub-bacias hidrográficas de Campinas, São Paulo, Brasil. Acta Brasiliensis, Patos, v. 3, n. 1, p. 1-7, 2019.

FENGLER, F. H. et al. Environmental quality of forest fragments in Jundiaí-Mirim river basin between 1972 and 2013. Revista Brasileira de Engenharia Agrícola e Ambiental, Campina Grande, v. 19, n. 4 , p. 402-408, 2015.

FRANCISCO, C. E. S. et al. Análise multicriterial na seleção de bacia hidrográfica para recuperação ambiental. Ciência Florestal, Santa Maria, v. 18, n. 1, p. 1-13, 2008.

GALVANI, E.; LIMA, N. G. B. Fotografias hemisféricas em estudos microclimáticos: referencial teórico-conceitual e aplicações. Ciência e Natura, Santa Maria, v. 36, nesp, p. 215-221, 2014.

GARCIA, J. M. et al. Environmental diagnosis of forest fragments belonging to the Santa Genebrinha ecological corridor, Campinas, São Paulo. Acta Brasiliensis, Patos, v. 3, n. 3, p. 97-105, 2019. DOI: http://dx.doi.org/10.22571/2526-4338262

GARCIA, J. M. et al. Uso de fotografias hemisféricas para avaliação da qualidade ambiental na Mata Santa Genebra, Campinas-SP, Brasil. Ciência Florestal, Santa Maria, v. 28, n. 1, p. 175-190, 2018.

GUARIZ, H. R. et al. Variação da umidade e da densidade do solo sob diferentes coberturas vegetais. Revista Brasileira de Agroecologia, [s. l.], v. 4, n. 2, p. 3293-3296, 2009.

GUIMARÃES, T. L. B. Determinação da cor do solo pela carta de munsell e por colorimetria.2016. Trabalho de Conclusão de Curso (Graduação em Agronomia) - Faculdade de Agronomia e Medicina Veterinária da Universidade de Brasília, Brasília, 2016.

HEMIVIEW. Hemi view user manual. Cambridge: Delta-t Devices, 2015. 85 p.

HONGYU, K; SANDANIELO, V. L. M.; OLIVEIRA JUNIOR, G. J. Análise de Componentes Principais: resumo teórico, aplicação e interpretação. Engineering and Science, [s. l.], v. 1, n. 5, p. 83-90, 2016.

INSTITUTO BRASILEIRO DE PESQUISAS ESPACIAIS (Brasil). Mapa de solos. São Paulo, 2020. Disponível em: http://www.dpi.inpe.br/Ambdata/mapa_solos.php. Acesso em: 07 fev. 2020.

LIMA-RIBEIRO, M. S. Efeitos de borda sobre a vegetação e estruturação populacional em fragmentos 
de Cerradão no Sudoeste Goiano, Brasil. Acta Botânica Brasilica, São Paulo. v. 22, n. 2, p. 535-545, 2008.

MATTAR, J. N.; KRUGER, C. M.; DZIEDZIC, M. Análise de indicadores ambientais no reservatório do Passaúna. Revista Engenharia Sanitária, Curitiba, v. 14, n. 2, p. 205-214, 2009.

NASCIMENTO, W. M. do.; VILLAÇA, M. G. Bacias hidrográficas: planejamento e gerenciamento. Revista Eletrônica da Associação dos Geógrafos Brasileiros, Três Lagoas, v. 5, n. 7, p. 102-121, 2008.

OLIVEIRA, D. M. S.; LIMA R. P. de.; VERBURG, E. E. J. Qualidade física do solo sob diferentes sistemas de manejo e aplicação de dejeto líquido suíno, Revista Brasileira de Engenharia Agrícola e Ambiental, Campina Grande, v. 19, n. 3, p. 280-285, 2015.

PANDOLFI, F. et al. Alterações na porosidade total do solo de um Latossolo Vermelho-Amarelo sob diferentes coberturas vegetais. In: ENCONTRO LATINO AMERICANO DE INICIAÇÃO CIENTÍFICA, 11.; ENCONTRO LATINO AMERICANO DE PÓS-GRADUAÇÃO, 6., 2007, São José dos Campos. Anais [...]. São José dos Campos: Universidade do Vale do Paraíba, 2007. p. 3412-3415.

PARENTE, H. N.; MAIA, M. O. Impacto do pastejo sobre a compactação dos solos com ênfase no Semiárido. Revista Trópica: Ciências Agrárias e Biológicas, Chapadinha, v. 5, n. 3, p. 3, 2011.

PAULINO, P da S. Atributos físicos como indicadores da qualidade do solo em sistemas de manejo no estado de Santa Catarina. 2013. Dissertação (Mestrado em Manejo do Solo) - Universidade do Estado de Santa Catarina, Florianópolis, 2013.

RALISCH, R. et al. Resistência à penetração de um Latossolo Vermelho Amarelo do Cerrado sob diferentes sistemas de manejo. Revista Brasileira de Engenharia Agrícola e Ambiental, Campina Grande, v. 12, n. 4, p. 381-384, 2008.

REICHARDT, K.; TIMM, L. C. Solo, planta e atmosfera: conceitos, processos e aplicações. Barueri: Manole, 2008.

RIBEIRO, W. V. A importância do corredor ecológico do igarapé Mirandinha para a sadia qualidade de vida no Município de Boa Vista. 2010. Dissertação (Mestrado Interinstitucional em Direito Ambiental) - Universidade Federal de Roraima e Universidade do Estado do Amazonas, Roraima, 2010.

ROSSETTI, K. V.; CENTURION, J. F. Sistemas de manejo e atributos físico hídricos de um Latossolo Vermelho cultivado com milho. Revista Brasileira de Engenharia Agrícola e Ambiental, Campina Grande, v. 17, p. 472-479, 2013.

SANTANA, O. A. et al. Relação entre o índice de avermelhamento do solo e o estoque de carbono na biomassa aérea da vegetação de cerrado. Ciência Florestal, Santa Maria, v. 23, n. 4, p. 783-794, 2013.

SANTOS, T. E. M.; MONTENEGRO, A. A. A.; SILVA, D. D. Umidade do solo no semiárido pernambucano usando-se reflectometria no domínio do tempo (TDR). Revista Brasileira de Engenharia Agrícola e Ambiental, Campina Grande, v. 15, n. 7, 2011.

SILVA, A. L. et al. Classificação de fragmentos florestais urbanos com base em métricas da paisagem. Ciência Florestal, Santa Maria, v. 29, n. 3, p. 1254-1269, 2019. DOI: http://dx.doi. org/10.5902/1980509830201

VASCONCELOS, R. F. B. et al. Qualidade física de Latossolo Amarelo de tabuleiros costeiros em diferentes sistemas de manejo da cana-de-açúcar. Revista Brasileira de Engenharia Agrícola e Ambiental, Campina Grande, v. 18, p. 381-386, 2014.

ZANCHI, F. B. et al. Estimativa do Índice de Área Foliar (IAF) e Biomassa em pastagem no estado de Rondônia, Brasil. Revista Acta Amazônica, Manaus, v. 32, n. 2, p. 335-348, 2009. 